\title{
O INSTITUTO DE ANTROPOLOGIA SOCIAL (EUA, BRASIL E MÉXICO): UM ARTEFATO DA RESPOSTA ANTROPOLÓGICA AO "ESFORÇO DE GUERRA"
}

\author{
Priscila Faulhaber
}

\section{Apresentação}

Este trabalho considera as implicações da instalação do Instituto de Antropologia Social (ISA) da Smithsonian Institution (SI) no Brasil e no México (1943-1952). Trata-se de mostrar como as diferentes condições institucionais de instalação de escritórios deste instituto no Brasil e no México envolveram diferentes discursos dos cientistas sociais a respeito da nacionalidade. Ambos os países promoveram, nos anos 1940, projetos de desenvolvimento nacional buscando criar um parque industrial com base na substituição de importações. Os projetos desenvolvimentistas governamentais requeriam a atuação de especialistas e, sendo assim, viabilizavam-se convênios internacionais para a capacitação de técnicos para o desenvolvimento. Em face de tal procura por especialistas, nas circunstâncias especiais da guerra, enquanto uma das respostas antropológicas às demandas da guerra, este instituto propunha-se a ser um instrumento de cooperação científica articulado à política de boa vizinhança dos EUA.

Tanto no Brasil como no México, intelectuais foram recrutados para atuar em organismos governamentais para participar da "construção nacional" (Peirano 1981, 1999) ou, o que toca mais diretamente a este trabalho, da formulação de discursos sobre a nacionalidade. No México, pensadores, professores e artistas foram convidados a substituir os cientistas que assessoravam o antigo regime nas tarefas de formulação e justificativa do projeto revolucionário (Batalla 1996:108). Durante o Estado Novo, os intelectuais também foram recrutados para atuar a serviço do governo brasileiro, que adotou critérios de mérito para definir quem estaria de fato servindo aos interesses da nação e não aos interesses dos políticos locais (Candido 1979). Não obstante, em ambos os países, os intelectuais produziram discursos que 
serviram para a justificação de um Estado que atendia prioritariamente aos interesses das elites.

Quando Julian Steward propôs ao Congresso norte-americano o projeto do ISA para lançar as bases de novas redes voltadas à America Latina, estava envolvido, pela situação singular da sua instituição em Washington, com redes interinstitucionais constituídas pelo "esforço de guerra", uma vez que tanto os antropólogos estadunidenses quanto os políticos e funcionários de governo eram mobilizados por valores antieuropeus na promoção da unidade pan-americana. No entanto, os contextos de estabelecimento das ciências sociais nos Estados Unidos, no Brasil e no México eram diferentes. A proposta de criação de um instituto baseado em princípios colaborativos e que evocava a simetria entre instituições científicas de diferentes países iria implicar relações assimétricas entre instituições, envolvendo diferentes discursos sobre nacionalidade.

Procura-se examinar fatos subjacentes às viagens de Steward ao Brasil em 1942 e ao México, em 1943. Neste país verificou-se uma sistemática presença de antropólogos estadunidenses que ali já vinham desenvolvendo continuadamente trabalhos de pesquisa de campo, vislumbrando possibilidades de colaboração interinstitucional permanente. Cabe circunstanciar o campo de relações observado no período histórico da Segunda Grande Guerra, quando o interesse do Departamento de Estado dos EUA na política de boa vizinhança possibilitou a obtenção de recursos para a proposta de criação do ISA. A ideia deste instituto surgiu ligada a projetos de cooperação pan-americana propostos por estabelecimentos norte-americanos e que envolveram uma dinâmica de apropriações e exclusões, caracterizada em termos de uma situação de "colonialismo científico" (Galtung apud Hymes 1967), o que implica, em outras palavras, que a força propulsora para a aquisição de conhecimento sobre um povo se encontra alhures, sendo deste modo determinada por interesses exógenos. Naquele momento, verificou-se a constituição de um grupo de especialistas predominantemente constituído por scholars estadunidenses, que manejavam um "fundo de representações simbólicas" (Elias 1982). Paralelamente, criavam-se e estruturavam-se domínios regionais de conhecimento. O discurso sobre almejar uma cooperação com bases simétricas encobria o enquadramento hierárquico das instituições latino-americanas, sendo que os representantes dos Estados Unidos vedaram-lhes de fato o acesso a informações estratégicas, produzindo-se deste modo assimetrias em termos de distribuição de poder e de participação em benefícios. Carecia-se, além disso, de um reconhecimento institucional mais adequado da contribuição dos profissionais dos países hospedeiros, cuja contribuição científica não era 
vista como de qualidade equivalente à dos pesquisadores estadunidenses, ainda que não se pretenda aqui desqualificar o legado científico de suas importantes séries editoriais e o lastro institucional deixado pelo ISA nos países da América Latina (Castro 2010).

Trata-se de focalizar etnograficamente detalhes das interações entre antropólogos e instituições nesse momento peculiar da história da antropologia que envolveu um significativo processo de circulação internacional de ideias. A análise da singularidade das relações antropológicas desencadeadas na situação de guerra faz com que hoje possam ser vistas como estabelecidas no terreno de um preâmbulo da Guerra Fria (Wax 2008). A complexidade documental relativa a esse momento inicial faz com que a análise a ele se restrinja, deixando para outros trabalhos destrinchar o que sucedeu no pós-Guerra.

\section{O discurso sobre a América no contexto da II Guerra: intervenção, luta pela hegemonia e participação dos intelectuais}

O discurso sobre a integração pan-americana remonta à Conferência Interamericana para a manutenção da Paz, em Buenos Aires (1936). Em 1939 foi criado em Washington o Institute for Inter-American Affairs. Nos anos 1940, foram criados diferentes organismos e redes articulados a essa ideia de integração pan-americana, entre eles o Committee for Latin American Anthropology (CLAA), em 1940, e o Ethnogeographic Board (comitê etnogeográfico, doravante EB) na Smithsonian Institution, em 1941. Ainda em 1942 passou a funcionar, em Yale, o Strategic Index of América. O Comitê Interdepartamental para Cooperação Científica e Cultural Pan-americana (CI), formado no interior do Departamento de Estado estadunidense, contava com representantes de várias agências do governo dos Estados Unidos voltados ao trabalho na América Latina. O CI coordenou a demanda orçamentária dos departamentos de governo, transmitindo as informações fundamentais e advogando as demandas nos comitês articulados ao Congresso. Os itens aprovados pelo Congresso eram transferidos às agências responsáveis (Foster 1967:177).

O EB, instalado na SI em 1942, passou a desempenhar o papel de intermediário em programas acadêmicos e planejamento governamental no campo dos estudos de área. Este comitê cuidou da criação de uma rede de especialistas, formando um corpo de conhecimento técnico e geográfico utilizado pelas Forças Armadas e agências de guerra para localizar rapidamente o especialista ou a informação requisitada. Ligado por vínculos de 
amizade a Duncan Strong, que dirigia o EB, Steward passou a atuar como um dublê de antropólogo federal e tecnocrata.

Indaga-se aqui, a partir da análise do que dizem os pesquisadores sobre suas práticas relacionadas ao ISA, como o poder se exerce na forma da pessoa social. Buscando operacionalizar ferramentas de análise da antropologia dos dias de hoje, trata-se de considerar, no exame de discursos produzidos no esforço de guerra e no despertar da Guerra Fria nos anos 1940, como as pessoas experimentaram de diferentes modos o mundo em que viveram, considerando como o poder operava em seus projetos e em suas práticas (Gavin 2004:216). Reconsiderando o conceito de hegemonia de Gramsci (Thompson 1963), importa antes refletir, antropologicamente, como o poder e as práticas culturais estão inter-relacionados na formação do sujeito. Na trilha de Roseberry (1994:361), considero aqui como a luta pela hegemonia operacionalizava então uma estrutura material e significativa na qual os sujeitos viviam, falavam sobre e atuavam em ordens sociais enraizadas em práticas de dominação. Roseberry (ibidem:362) relativiza a definição de um "campo de forças" definido como uma oposição magnética bipolar, argumentando que a realidade é infinitamente mais complexa, envolvendo múltiplos lugares de dominação e experiências de luta contra a opressão. Tal luta pela hegemonia abarca estruturas de sentimento e subjetividades sociais (Williams 1977) que, embora sendo profundamente coercitivas, nem sempre são vivenciadas como tal (Syer 1994:373). Entendo tais estruturas como veículos culturais que condicionam as práticas enquanto habitus (Bourdieu 1982), como resultado de cadeias de sentido interconectado historicamente, cujo exame permite analisar estratégias nos domínios da cultura.

Trabalha-se aqui com a discussão sobre "representações do intelectual" de Edward Said (1996). De acordo com Said, seriam considerados por Gramsci intelectuais orgânicos aqueles que, ativamente envolvidos na sociedade, procuram transformar mentes e expandir mercados. Por definição, estão sempre envolvidos com o fazer, com o movimento. Considerando a "representação social" como um instrumento heurístico de caráter genérico, a opção aqui foi focalizar o exame das recorrências e do implícito discursivo em depoimentos dos cientistas sociais destacados, os conceitos por eles empregados e as práticas sociais nas quais estavam inseridos. Considerase aqui que tais depoimentos, conceitos e práticas, embora heterogêneos, estão relacionados em "redes de formulações" que constituem campos de articulação interdiscursiva, cujo exame permite considerar analiticamente a dimensão constitutiva das práticas sociais (Maingueneau 1989:115).

Said imprime uma conotação radical à sua definição de intelectual, afirmando como característica dos intelectuais seus princípios mínimos de 
moralidade e, como decorrência disto, sua disposição para dizer "a verdade ao poder" (Said 1996:65). Examinam-se aqui relatórios, depoimentos e ensaios nos quais tais pesquisadores descreveram suas práticas na organização do ISA. Sua preocupação com o registro sistemático em relatórios do que ocorreu, bem como com o arquivamento de sua correspondência torna possível detalhar a presente reflexão. Consideram-se os discursos dos cientistas sociais sobre a nacionalidade no Brasil e no México, procurando-se entender como pesquisadores nativos destes países compreendiam que sua participação institucional abria ou não alternativas para os próprios projetos em termos de suas trajetórias profissionais. Sendo assim, trata-se antes de entender aqui como os pesquisadores nos dois países subalternizados procuravam capturar as alternativas viáveis, evocando possíveis cadeias de significado. Isto nem sempre representou uma efetiva oposição ao que era oferecido, mas uma tentativa de operacionalização das possibilidades, adequando demandas do Estado e seus interesses intelectuais, produzindo discursos e práticas de construção nacional. Importa, assim, considerar como pesquisadores como Julian Steward, George Foster e Donald Pierson representavam o ISA como um projeto institucional e quais respostas sua proposta despertou em práticas e discursos de pesquisadores no México e no Brasil. Não cabe nos limites deste trabalho estabelecer a análise da atuação do ISA no Peru, na Colômbia e na Guatemala, tal como realizada por Castro (2010).

\section{Nacionalismo de Estado no México e no Brasil}

Nos anos 1940, tanto o México quanto o Brasil caracterizavam-se como Estados nacionalistas e desenvolvimentistas, que usavam a participação popular como apoio político para atingir metas pautadas no centralismo político. Nos dois países, os Estados atuaram por meio de uma política de substituição de importações, visando fortalecer a indústria nacional e o mercado interno, o que resultava em contradições, porque a industrialização criou a necessidade de procurar investimentos externos.

No México, registrou-se um esforço desde os tempos revolucionários da primeira década do século XX de romper com a influência hispânica e erigir a construção nacional mexicana em termos de valores pan-americanos, tomando a imagem do índio como símbolo nativista, que também inspirou no Brasil a fundação, em 1919, da instituição indigenista, seguindo um credo positivista baseado em princípios de integração nacional segundo práticas militares, inicialmente sem nenhuma participação dos antropólogos que, 
inclusive, se opunham aos valores do indigenismo. No México, antropólogos foram incorporados ao aparelho indigenista, desde a sua formação, com uma função educacional e de pesquisa, sendo a imagem do índio um dos pilares dos escritos da chamada "época de ouro" da antropologia mexicana. A vizinhança geográfica e a proximidade com os valores pan-americanos propiciaram a aproximação com os centros antropológicos dos EUA que deram suporte material para contrabalançar a influência europeia. A antropologia mexicana contou, assim, com a colaboração dos seus vizinhos estadunidenses. Nelson Rockefeller e a Carnegie Foundation apoiaram projetos que resultaram, em 1939, na fundação do Instituto Nacional de Antropologia e História, no qual funcionou a Escola de Antropologia e ao qual estiveram associados o Instituto Indigenista Pan-Americano e a Revista América Indígena. Concorreram para a colaboração as pesquisas de Robert Redfield e Sol Tax, a partir das quais Julian Steward e George Foster viram um solo fértil para instalar o Instituto de Antropologia Social. Foram realizados no México grandes congressos pan-americanos, cujos promotores visavam "exportar" o indigenismo mexicano, sem que, no entanto, as elites e o Estado brasileiro fossem receptivos a um indigenismo revolucionário (Lima 2005:202), embora o indigenismo mexicano dos anos 1940 estivesse muito longe do espírito revolucionário do início do século. No México pós-revolucionário, o que estava em jogo não era a constituição, mas a organização e o status do partido revolucionário governista, que foi duas vezes reconfigurado com a sucessão ao poder de um novo "presidente forte", representando uma nova tendência política. Em 1946, o presidente Miguel Alemán denominou-o PRI (Partido das Instituições Revolucionárias), que representou, com sua maturidade, uma guinada para a direita (Needler 1967:126).

O "corolário Roosevelt" da Doutrina Monroe foi concebido com o reconhecimento pelos EUA das reivindicações dos governos detentores de divisas, bem como com a relutância em ver poderes europeus intervirem no hemisfério ocidental. A ação governamental direta transformou-se em intervenção militar em benefício dos investidores que aplicavam nas economias de países vizinhos, tal como ocorreu na política da administração Roosevelt de restrição sobre a expropriação dos interesses petroleiros em 1938. A "mexicanização" dos anos 1930 significava que nenhuma empresa econômica operando no México poderia ser controlada por estrangeiros, sendo que as decisões que afetassem a economia mexicana deveriam ser tomadas unicamente por mexicanos. Isto claramente implicava um apelo ao nacionalismo econômico. No entanto, a medida na prática determinava que pelo menos $51 \%$ do estoque de uma empresa deveriam ser apropriados por mexicanos. O efeito de tal medida foi a canalização de capital mexicano 
em empresas produtivas que continuaram sendo controladas por capitais estrangeiros, a despeito do apelo nacionalista que considerava suspeito o investimento yankee (Needler 1967:169).

A substituição de importações acarretou a expansão de um sistema capitalista predatório, selvagem, escorado pelo setor público e azeitado pela chamada economia mista. As políticas de modernização do meio rural aumentaram a sujeição do campesinato indígena à sociedade dominante, que não abria mão do uso do capital em função de seus próprios interesses. Nas palavras de Bonfil Batalla (1996), "o México rural permaneceu subjugado ao México industrial".

O processo desenvolvimentista mexicano a partir dos anos 1940 determinou outro tipo de "mexicanização", promovendo, através do "colonialismo interno" (Casanova 1962), as políticas nacionais em termos da denegação da civilização mesoamericana. Tal denegação transfigurou o fetichismo da imagem do índio na criação de uma cultura imaginária que passou a afirmar, ideologicamente, a mestiçagem para desclassificá-la aos olhos da América liberal. Ao passo que a realidade contraditória do inadmissível inconsciente colonial do chamado "México profundo", tal como proposto por Bonfil Batalla (1996), desmistificou tal imaginário, mostrando, entre suas contradições, como os próprios antropólogos participavam da elite letrada nacional (Lomnitz 2005) que dominava o interior do país, bem como a população pobre e os índios, submetidos a um aparato de Estado que se sustentava, tal como no Brasil, em ideologias étnicas e de dominação (Cardoso de Oliveira 1978:81).

Já quanto às relações dos Estados Unidos com o Brasil, havia um antigo intercurso, apesar de não se tratarem de dois países com limites confinantes, como ocorria entre EUA e México. EUA foi o primeiro país a reconhecer a independência do Brasil (1822). Tais vínculos se estreitaram no século XX quando o Brasil defendeu a doutrina Monroe durante a Quarta Conferência Pan Americana. Em troca, os EUA forneceram garantias para a aspiração brasileira de liderar países latino-americanos. O discurso de igualitarismo entre países americanos era uma estratégia para a consecução da hegemonia dos EUA, garantindo, por meio da persuasão, seus próprios interesses.

Quando os EUA entraram na guerra após Pearl Harbor (dezembro de 1941), o Brasil uniu-se às forças aliadas contra o Eixo. Isto forçou o país a desistir da sua política de equidistância pragmática em assuntos comerciais. Em troca, os EUA equiparam em termos militares e industriais seu estratégico "bom vizinho". Esta aliança, decisiva para quebrar, ainda no início de 1942, a resistência do Chile e da Argentina, tornou viável a declaração de oposição dos países sul-americanos contra o Eixo. A propaganda pan-americana concorreu para tal aliança. A entrada do Brasil na guerra 
foi disputada principalmente por sua situação estratégica na América do Sul e seu papel de supridor de matéria-prima, tal como ferro, manganês e, sobretudo, borracha. Para os EUA, este produto era visto como o verdadeiro "nervo da guerra" pois, após o bombardeamento de Pearl Harbor, os EUA perderam 97\% de suas fontes de suprimentos (Knorr apud Martinello 2004).

Entre os acordos de Washington (1942), aquele para incrementar a qualidade da borracha amazônica destinou fundos especiais para um programa de saúde para melhorar as condições sanitárias na região. Este programa de saúde resultou na criação do SESP (Serviço Especial de Saúde Pública). Do ponto de vista dos EUA, o SESP visava implantar um sistema de saneamento e de apoio à saúde dos trabalhadores em áreas em que eram desenvolvidas atividades econômicas de interesse dos EUA durante a situação de guerra. O Estado Novo objetivava aproveitar este apoio para consolidar sua presença em áreas ainda não suficientemente estruturadas do ponto de vista administrativo, no sentido de ampliar o poder federal em áreas submetidas às oligarquias, investindo grande capital simbólico nos processos de construção nacional (Campos 2006:55). O Office of the Coordinator of Inter American Affairs (OCCIAA) era encarregado oficialmente do domínio cultural do programa, incluindo o planejamento revolucionário de suprimento agrícola para os soldados da borracha, uma verdadeira agenda de atividades de propaganda. Não obstante, o sistema de exploração desencorajava os extratores endividados a incrementar a produção da borracha. Como destacou Wagley, que prestava serviços antropológicos ao Serviço Especial de Saúde Pública (SESP) com apoio do OCCIAA, o plano governamental de introduzir inovações tinha, no entanto, falhas que de fato produziram efeitos positivos muito aquém das necessidades dos extratores e ribeirinhos que viviam em precárias condições de subsistência na Amazônia (Wagley 1953).

Em uma situação estrutural de colonialismo interno semelhante ao mexicano (Cardoso de Oliveira 1978), circunstanciais e episódicas medidas de assistência promovidas pelo Estado brasileiro com o apoio da cooperação interamericana não foram suficientes para facilitar a vida dos soldados da borracha. Os suprimentos a eles destinados eram vendidos por preços extremamente altos nas áreas afastadas da floresta. Se a situação dos nordestinos transportados para a guerra era precária, o que não dizer dos índios que lá viviam, expostos a todos os tipos de ameaças e submetidos ao indigenismo de Estado, entendido como um aparato burocrático que servia como um instrumento de administração pública, atuando no sentido de garantir uma estrutura de dominação constituída historicamente. No Estado Novo, a estrutura do positivismo militar foi transformada de modo que pudesse se ajustar ao modelo do Bureau of Indian Affairs dos Estados Unidos, criando, 
em 1942, a Sessão de Estudos do Serviço de Proteção aos Índios (Lima 2005:207). No entanto, a situação histórica dos índios latino-americanos era desconhecida dos acadêmicos dos EUA, que os pensavam como mais próximos de uma situação original em termos de uma comparação com os índios meso e norte americanos, dentro da qual era interessante considerálos de modo especial em função dos projetos da SI, como o Handbook of South American Indians, do qual um volume inteiro se ocupou dos índios das florestas tropicais (Steward 1948).

\section{O ISA na Smithsonian: um artefato criado em tempos de "esforço de guerra"}

No início dos anos 1940, pesquisadores norte-americanos que desenvolveram projetos na América Latina coletaram informação para fins políticos e trabalharam apoiados por programas criados especificamente para a situação de guerra (Delpar 2008). Tais programas eram definidos por instituições governamentais ou filantrópicas que partilhavam uma série de valores e atitudes relacionados a seu serviço como especialistas e consultores para o desenvolvimento de países latino-americanos, apresentando relatórios detalhados para organismos como o Commitee of Interamerican Affairs (CIAA) ou mesmo diretamente para o Office of Strategic Services (OSS), embrião da Central Intelligence Agency (CIA).

O posicionamento de Boas contra a atuação de arqueólogos como espiões durante a Primeira Grande Guerra Mundial desencadeou debates públicos sobre a legitimidade da articulação de projetos antropológicos com demandas da guerra. Este posicionamento se dava tanto devido ao seu engajamento socialista quanto a uma estratégia de afirmação diante tendências antigermânicas em setores da academia nos EUA (Price 2008:14). Subjacente à ideia de colocar a ciência a serviço da verdade estava uma postura de "neutralidade axiológica" considerada inviável por circunstâncias do campo científico na época. O comprometimento dos membros da cúpula da AAA (American Anthropological Association) com o status quo que estava sendo levado a público gerou a célebre "censura" a Boas (Stocking 1968). Já nos anos 1940 parecia ponto pacífico que a participação nos órgãos de informação voltados para a situação de guerra era um meio que justificava fins, como a integração americana e a luta contra o nazismo. Isto não representou uma ruptura total com o relativismo antropológico, que continuou sendo empregado como uma marca da antropologia cultural, ainda que usado em dispositivos do campo científico que serviam a propósitos da guerra. 
Nos anos que imediatamente antecederam à Segunda Guerra Mundial, o Social Sciences Research Council (SCRC) e o American Council of Learned Societies (ACLS) elaboraram os programas de estudos de área fora dos Estados Unidos, focando primeiramente nos países asiáticos. O ACLS estabeleceu o Comitê de Estudos Latino-americanos (JCLAS), sendo este o primeiro de seus comitês a promover estudos de uma grande área pensada não em termos culturais, mas estratégicos. Durante a guerra verificou-se uma "divisão do trabalho" entre os continentes. Enquanto o Office of Strategic Services (embrião da CIA), capitaneado por Willian Donovan, cuidava do Oriente, o Office of the Coordinator of Interamerican Affairs (OCIAA) agia com certa autonomia diante do Serviço de Inteligência Especial do FBI, dirigido por J. Edgar Hoover (Price 2008:108). Ao criar o Instituto de Assuntos Interamericanos (IIAA), Rockefeller passou a ter relativo controle sobre a economia da coleta de informação sobre a América Latina, gerindo o provimento de recursos federais para iniciativas voltadas à região, associando pesquisa antropológica com assistência e intervenção dos EUA para propósitos de desenvolvimento. O Comitê Interdepartamental para Cooperação Científica e Cultural, pouco antes estabelecido pelo Departamento de Estado dos EUA, concorreu para delimitar tal associação entre planejamento burocrático e pesquisa acadêmica.

Não havia, contudo, unanimidade dos antropólogos diante das políticas de Estado. Muitos se mostraram insatisfeitos quando seus pareceres não foram levados em consideração. Cora Dubois, buscando desenvolver seu trabalho em consonância com os sujeitos pesquisados, expôs o desconforto dos povos insurgentes com as estratégias neocoloniais. Bateson mostrou seu pessimismo em relação às aplicações da ciência, defendendo a prioridade da compreensão enquanto aspecto fundamental do conhecimento científico, diferentemente de Margareth Mead, que advogava pela maior responsabilização dos cientistas sociais, uma vez que não relutava em defender que a antropologia poderia contribuir para a solução de problemas práticos da sociedade (Price 2008:240). Embora já se levantassem problemas éticos no posicionamento diante dos órgãos pagadores, as diferentes posições não lograram naquele momento um consenso que se formalizasse em termos de um código de ética profissional. Uma vertente dos antropólogos americanos procurou universalizar a antropologia dos EUA privilegiando o estudo do "caráter nacional na perspectiva da 'Cultura e Personalidade'" (Neiburg \& Goldman 1998:60).

Steward, em um caminho um pouco diferente, percebeu que era possível acionar o CI como um dispositivo administrativo para tornar possível o desenvolvimento de três abrangentes projetos: o Handbook of South 
American Indians, a Revista Acta Americana e o próprio ISA, focalizado no presente trabalho. Steward idealizou tais projetos na busca de alternativas para a antropologia e como fontes de recursos para seus colegas, que ainda sentiam na pele os efeitos da Grande Depressão dos anos 30 e que se dispunham a trabalhar para patronos governamentais. A Escola de Cultura e Personalidade não tardou a ser considerada ultrapassada pela antropologia social proposta por Steward, que procurava cunhar instrumentos de análise histórico-comparativos em lugar de tomar a cultura por si mesma (Carta de Steward a Strong de 10 de abril de 1946, no fundo Strong nos National Anthropological Archives, doravante NAA). A Sociedade pela Antropologia Aplicada foi formada nos EUA em 1942, congregando pesquisadores que trabalhavam com antropologia da ação, antropologia do desenvolvimento e estudos de comunidade (Willigen 2002). A congregação de tão diferentes ethos dentro da sigla antropologia aplicada como uma forma de "engenharia social" foi viabilizada em circunstâncias especiais da Segunda Guerra Mundial, cabendo diferenciar esta concepção preliminar de sua posterior redefinição de acordo com as necessidades neocoloniais consubstanciadas na Guerra Fria (Price 2008:51).

Steward, no entanto, pensava de maneira própria sobre as implicações da antropologia aplicada, sendo completamente cético quanto às possibilidades de aplicabilidade da ciência. Tendo iniciado sua carreira no Bureau of American Anthropology (BAE) da Smithsonian, na posição de antropólogo consultor do Bureau of Indian Affairs, percebeu, no entanto, que os conhecimentos que assimilou na academia eram transformados e usados em função de questões práticas nas consultorias. Lidando com os dirigentes de agências governamentais pelo ângulo da "diplomacia" indígena, vislumbrou a possibilidade de firmar sua posição no BAE, como autor antropológico científico, ao realizar a mediação entre agências governamentais e o meio acadêmico, respaldado pela interação com aqueles que lidavam com questões práticas (Kerns 2003:210). As questões antropológicas envolvendo os índios da América do Sul estavam na ordem do dia do ponto de vista da política de boa vizinhança durante o esforço de guerra, tempo em que a luta contra o fascismo era uma unanimidade, de modo que o papel de editor do Handbook of South American Indians lhe daria grande visibilidade.

Já no ISA, Steward podia colocar em prática suas concepções teóricas no sentido de deslocar a atenção antropológica das culturas indígenas tradicionais para o processo de transformação dos povos desenraizados de suas comunidades para serem transformados em "proletariado" nacional (Patterson \& Lauria-Perricelli 1999:220). Sua abordagem multilocalizada da ecologia e da "mudança cultural" era apenas parcialmente inovadora, 
estando impregnada de paradigmas preexistentes. Seu foco na mudança cultural adveio dos estudos de "aculturação", cristalizados na antropologia dos EUA desde 1930 que, no entanto, embeberam sua posterior definição de "subculturas" dentro de sociedades nacionais (Steward 1955). O foco nas políticas da administração aparece como uma apropriação inconfessa de conceitos e práticas da antropologia anglo-saxã. A ênfase em estudos regionais e de comunidade também não era obra sua, uma vez que tais estudos foram introduzidos no México por Ralph Beals e Robert Redfield. Steward sabia que os estudos de mudança cultural, administração, regionais e de comunidade eram conduzidos em Estados nacionais modernos para identificar e promover as perspectivas do desenvolvimento econômico capitalista em áreas de fronteira.

Em tais propostas conceituais aplicadas estava em jogo a ideia de intervenção, esta significando para os estrategistas norte-americanos, liderados por Franklin Delano Roosevelt, um corolário da Doutrina Monroe, através da definição de uma política de Boa Vizinhança que era, antes de tudo, uma estratégia para demonstrar que poderia ser legítimo se opor ao expansionismo europeu. Estava em jogo para os estrategistas estadunidenses a busca da construção da hegemonia nas Américas, desestabilizando a influência europeia. Entende-se aqui a luta pela hegemonia nos usos do poder para organizar o consenso sobre a ideia de que a América deveria ser governada pelos próprios americanos, usando o poder, igualmente, para assegurar o projeto político de controle por parte dos Estados Unidos caracterizado como um processo de "americanização".

Afirmou Steward em carta para George Foster (22/11/43, NAA/SI) que os ânimos para estreitar os laços entre as repúblicas americanas abriam a possibilidade de apropriação de recursos econômicos no próprio Congresso dos Estados Unidos para a criação do ISA como um instituto colaborativo dentro dos princípios da cooperação latino-americana. Tal instituto, desde sua fundação, era apresentado como um artefato de intervenção em canais que podiam verter recursos para a cooperação científica.

Os relatórios da Smithsonian correlacionam diretamente a pesquisa científica e a guerra. No relatório do ano fiscal de 1941, foram assinalados os problemas conectados com a defesa nacional, determinando que todos os recursos institucionais fossem destinados a pesquisas neste âmbito. O relatório menciona que a demanda a este respeito cresceu notadamente após Pearl Harbor, sendo apontado, no início de 1942, um Comitê de Guerra com o propósito de integrar o esforço bélico. No relatório de 1942 afirma-se que, no fechamento do ano fiscal, 33 empregados da instituição integraram-se às Forças Armadas e cinco foram transferidos para servir a diferentes agências 
de guerra. Dez deles eram membros do corpo científico da instituição. Muitos dos que permaneceram na instituição devotaram tempo integral a projetos de guerra designados pelo Exército, pela Marinha ou por agências de guerra, e todos os demais membros ocuparam-se em algum grau de tais projetos, dependendo da extensão em que seu conhecimento especial era demandado.

As ações da instituição foram mantidas apenas no que se referia à manutenção das atividades essenciais, no que dizia respeito às coleções e aos arquivos. Todos os outros projetos foram suspensos, privilegiando-se unicamente as atividades relacionadas com uma cooperação mais próxima com as outras repúblicas americanas. Tal cooperação era tida como de vital importância para melhores relações com países vizinhos em tempos considerados como de emergência.

Steward concebeu o ISA preliminarmente em julho de 1942, apresentando um projeto para sua operacionalização diante do Comitê Interdepartamental para Cooperação com as Repúblicas Americanas em agosto do mesmo ano. Seu propósito expresso era implementar treinamento cooperativo em ensino antropológico e pesquisa em outras repúblicas americanas. O projeto foi apresentado como um programa permanente, sendo contudo estruturado como uma resposta emergencial ao esforço de guerra, cujos principais projetos foram conduzidos à instituição por meio de comitês executivos que ali funcionavam, bem como através de contatos institucionais com outras agências, sendo tratados como assuntos de caráter estritamente confidencial que envolviam diferentes ramos das ciências - antropologia, biologia, geologia, física e meteorologia. Com o término da guerra, surgiram outras prioridades e a diretriz pan-americanista seria relegada a um segundo plano até sua extinção em 1952 (Figueiredo 2009).

\section{Viagem ao Brasil}

Em dezembro de 1942, Steward visitou o Brasil para estabelecer contatos a fim de viabilizar seus projetos na SI. Além de conhecer representantes de instituições brasileiras com vistas a instalar um escritório do ISA em uma delas, também almejava entrar em contato direto com autoridades acadêmicas para tratar da sua participação no Handbook of South American Indians. Em Belém, encontrou Curt Nimuendaju, que trabalhava como colaborador de Robert Lowie com recursos do Instituto de Pesquisa Social da Universidade da Califórnia, em Berkeley, desde 1932. Steward adquiriu, com recursos da Rockefeller Foundation, o famoso mapa etno-histórico produzido pelo etnógrafo alemão naturalizado brasileiro. Também encontrou 
Charles Wagley, juntamente com aqueles que Steward considerou os seus colaboradores brasileiros em pesquisa de campo no Pará, entre eles Eduardo Galvão, que mais tarde iria estudar com Wagley e Steward na Universidade de Columbia. No Rio de Janeiro, teve encontros de trabalho com Heloisa Alberto Torres, Artur Ramos e Roquette Pinto. Em São Paulo, esteve com Donald Pierson, Herbert Baldus e Radcliffe-Brown. Em carta de 9 de julho de 1942, dirigida a Robert Lowie, Steward menciona, com ironia: "Parece que a Inglaterra gostaria de ver um pouco de vida nova em sua antropologia colonial. A falha britânica certamente tem sido uma lacuna antropológica em alto grau, ainda que seja difícil afirmar se a falta reside nos antropólogos ou nos administradores" (ISA/NAA/SI). A mira de Steward se volta não somente aos vínculos da antropologia britânica com a administração colonial, como às disputas de poder entre os profissionais que ele contatou nos centros de pesquisa do sul do Brasil.

Wagley recomendou fortemente a Steward estabelecer o escritório do ISA no Museu Nacional, que tinha mais tradição em pesquisa de campo antropológico que a ELSP (em carta a Steward de 5 de outubro de 1942 depositada no NAA, mencionando explicitamente a diretora do Museu Nacional, Heloisa Alberto Torres, que desde os primeiros tempos de sua trajetória profissional, influenciada por Roquette Pinto, apoiara as pesquisas de campo. Com esta perspectiva, inspirara a formação de antropólogos profissionais como Curt Nimuendaju, Eduardo Galvão e Luís de Castro Faria (Castro Faria 1978; Correa 1997). Wagley mantinha fortes laços de amizade com Heloisa, reiterados em copiosa correspondência. Em suas cartas a ele dirigidas com carinho, a antropóloga demonstra várias vezes que fazia "questão cerrada" que quaisquer planos de antropólogos dos EUA no Brasil tivessem o Museu Nacional à frente (Correa \& Melo 2008:208). Concorria para o interesse em estabelecer o ISA no Museu Nacional o fato de que esta instituição era considerada um centro importante de antropologia sintonizado com os centros de antropologia estadunidenses, registrando-se uma colaboração anterior com a Universidade de Columbia, através da qual Wagley ministrara um curso apoiado pela fundação Guggenheim. A principal argumentação de Wagley para fazer jus ao seu pacto de lealdade com Heloisa e com o Museu Nacional consistia na característica da Escola de Sociologia e Política de São Paulo que, como o próprio nome diz, era a de um nicho propriamente sociológico e politológico, ministrando disciplinas em que já havia um maior campo de atuação para as ciências sociais dos EUA, cuja influência na época ainda era menos expressiva que as europeias (Massi 1989). Grosso modo, destinava-se mais especificamente à formação de sociólogos profissionais do que antropólogos com experiência de pesquisa de campo. 
Steward atendeu à sugestão de Wagley: além de ter convidado Heloisa para produzir uma nota de não mais que 3.000 palavras para o Handbook sobre arqueologia do Marajó, propôs-lhe, em carta de 11 de outubro de 1942, a colaboração na criação de seu almejado "instituto colaborativo". A ideia seria enviar, se houvesse fundos disponíveis, um grupo de pesquisadores americanos, formado por um linguista, um geógrafo humano ou antropólogo físico, ao Museu Nacional, os quais deveriam se instalar em um espaço para ensino e em um laboratório para pesquisa. Em carta de 1 de dezembro de 1942, Donald Pierson escreve a Steward mostrando como entendia que a ELSP seria o lugar mais propício para a instalação do ISA e apresentando as características que via como negativas da Universidade do Rio, do Museu Nacional, de Roquette Pinto e de Heloisa Alberto Torres, ressaltando que as características pessoais dela não eram muito bem vistas em São Paulo. Heloisa demorou alguns meses para responder à proposta de Steward, mas quando respondeu, apresentou uma veemente negativa. Afirmou em carta de 19 de abril de 1944 (ISA/NAA/SI): "a chegada de uma equipe inteira de cientistas à minha aldeia em tal tempo [de guerra] iria causar a mesma confusão da instalação de um grande grupo de pesquisadores em uma tribo indígena não acostumada a lidar com estrangeiros". Ela declarou que teria interesse, sim, na colaboração de um único antropólogo. Já manifestara junto a Boas e a Guggenheim sua predileção por Wagley, tanto por suas contribuições antropológicas quanto por suas qualidades pessoais.

Em manifestações anteriores, como em carta de 2 de janeiro de 1941 dirigida a Boas (depositada em Boas Professional Papers, consultado na forma de microfilme no Instituto Getty de Pesquisa de Los Angeles), ela já afirmara a dificuldade de relacionamento dos estudantes brasileiros com William Lipkind, linguista recomendado pela Universidade de Columbia. Ruth Landes levantara a suspeita de que, como diretora do Museu, Dona Heloisa não queria se chocar com setores das elites brasileiras simpatizantes com o nazismo. No mesmo dia, Dona Heloisa reiterou a mensagem dirigida a Boas em carta (de 2/1/1941) ao presidente da Fundação Guggenheim, na qual descartou definitivamente a presença de Lipkind no Museu Nacional. Justificou sua recusa porque ele, inúmeras vezes, demonstrara não estar de fato interessado em cooperar com o Museu Nacional, nunca tendo lhe enviado relatório de sua missão. Heloisa referiu-se ademais ao espírito crítico dos alunos, que reagiram ao seu comportamento de superioridade (Correa \& Melo 2008:212). Lipkind trabalhava para o Office of War Information, juntamente com outros antropólogos da Escola de "Personalidade e Cultura" que atuavam no Oriente (Price 2008:172). Finalmente, Heloisa conseguiu que Boas apoiasse a atuação de Wagley com uma bolsa da Guggenheim. 
Filha de um expoente do pensamento social brasileiro, antropóloga, dirigente do Museu Nacional e integrante da meritocracia científico-cultural do Estado Novo, Heloisa vinculou-se a projetos governamentais de caráter nacionalista, participando ativamente do Conselho de Fiscalização das Expedições Artísticas e Científicas Nacionais, do Instituto do Patrimônio Histórico e Artístico Nacional e do Conselho Indigenista Nacional, mobilizada pela salvaguarda do patrimônio científico como expressão da cultura nacional. Também prezava suas interlocuções no estrangeiro e defendia uma atuação das instituições brasileiras no campo internacional, tendo representado o Brasil em eventos do porte do projeto do Instituto Internacional da Hiléia Amazônica, vinculado à UNESCO, e liderado a cooperação com Universidades de prestígio, como a Universidade de Colúmbia (Correa 1997, 2000). Ainda que tivesse grande apreço por essas colaborações internacionais, neste caso a resposta a Steward denotou posicionamento de defesa da autonomia da sua instituição, envolvida que estava na sua estruturação emergencial para a situação de guerra (CFDA/MAST 11/01/1923).

Heloisa enfatizou em sua carta de recusa seu lado feminino - um posicionamento de gênero (Correa \& Melo 2008), já comparado com o de outras mulheres antropólogas que assim agiram (Correa 2003). Neste caso, possivelmente intuía as preferências de Steward em lidar com homens, recentemente destacadas em sua biografia (Kerns 2003). A resposta de Heloisa a seu poderoso interlocutor manifesta uma reação feminina às tensões pessoais e institucionais e à maneira de Steward de ver as relações com os brasileiros. Note-se ainda que, no caso de suas interações no Brasil, além de sua disposição para trabalhar com antropólogos estadunidenses, Kerns destaca em sua biografia o seu mal-estar, que o levara a interromper sua viagem à América do Sul em 1938. Tais indicações, na leitura da biografia, caracterizam este desconforto como um tipo de "nostalgia do gabinete", um tipo de "condição patológica de saudade de casa" (Rosaldo 2003:71) que fizeram com que, a partir dessa sua malograda viagem, ele abandonasse a pesquisa de campo e buscasse conquistar posições acadêmicas usando seus contatos nos corredores da Smithsonian, onde atuou como um mediador entre pesquisa científica e agências burocráticas voltadas à situação de guerra.

Tais singularidades da trajetória de Steward permitem avaliar que quando esteve no Brasil estava mais predisposto a trabalhar conjuntamente com antropólogos estadunidenses do que travar relações igualitárias com "autoridades locais" no Brasil. Movido por sua fé em ciência behaviorista, ele certamente não via com bons olhos as reivindicações de autonomia da diretora do Museu Nacional. Seu menosprezo à interlocutora, classificando-a 
no viés de seu envolvimento de corpo e alma com os projetos nacionais do Estado Novo, parece, no entanto, um simplismo, uma vez que ela mantinha em alta conta as interlocuções internacionais, buscando defender junto ao próprio Vargas apoio à colaboração com instituições norte-americanas.

Implícita à recusa de Heloisa está a sua constatação do caráter desproporcional das relações propostas, caracterizadas por assimetria em uma correlação de forças, bem como dissimetria entre meios institucionais e científicos acumulados por instituições dos dois países. Steward manifestava interesse de que seus colegas e conterrâneos estudassem no Brasil, mas não oferecia em contrapartida condições para que os brasileiros estudassem ou fizessem pesquisa nos EUA. Assimetria que Wagley contribuiu para romper quando logrou, valendo-se da "política de boa vizinhança" dos EUA, que Eduardo Galvão fosse estudar em Columbia. No entanto, a preocupação de Wagley em treinar os estudantes brasileiros em antropologia antes e durante sua ida a campo parece um esforço singular em construir vínculos horizontais com o Brasil. Apesar do interesse dos EUA durante a guerra em cooperar com a América do Sul, de modo nenhum se pode afirmar que esta tenha sido a regra no Brasil e no México.

Segundo interpretação de George Foster (1989), vários fatores influenciaram a concepção de Steward sobre o ISA. Um deles foi a impressão causada durante sua viagem ao Brasil, quando entrou em contato com o trabalho da Escola Livre de Sociologia e Política liderada por Cyro Berlink. Lá encontrou um departamento de Sociologia e Antropologia recentemente criado, bem como uma divisão de pós-graduação, com a colaboração de professores estrangeiros, como Donald Pierson, A. R. Radcliffe-Brown e T. Lynn Smith. Pierson, que se destacou por sua longa permanência em uma instituição latino-americana (Correa 1987), já havia passado muitos anos na Escola, antecedendo a Wagley em suas interações no Brasil. Steward ficou impressionado com os benefícios derivados de um esforço continuado, em contraste com o padrão usual de estadia de apenas um ano de intercâmbio. A boa impressão de Steward com tal interação inspirou-lhe, nas palavras de Foster (1989:123), "a ideia de séries de clones de Pierson", que pudessem realizar o sonho de Steward de ensinar "ciência behaviorista" em universidades e centros de pós-graduação na América Latina. É possível que os esforços colaborativos de Rowe em Cuzco tenham também impressionado Steward. Sendo assim, o convite de Steward a Dona Heloisa parece ter sido motivado mais por questões políticas, por seu apreço a Wagley, sendo que de fato Steward tinha em mente a formalização do apoio a Donald Pierson - como pôde efetivamente fazê-lo após a recusa de Heloisa — que anteriormente já o considerara um exemplo a ser seguido por sua atuação na ELSP. 
Mas a recusa de Heloisa Alberto Torres foi episódica e, de maneira geral, os cientistas nomeados pelo ISA foram bem aceitos nas instituições da América Latina. A recusa por parte do Museu Nacional e a preferência pela ELSP geraram um impasse: de fato pareceria estranho a um instituto colaborativo denominado como de Antropologia Social, imediatamente após tal recusa, estreitar a colaboração com um instituto voltado a estudos sociológicos. Tal impasse causou um hiato na documentação do ISA em relação ao Brasil, período documentado em copiosa correspondência entre Wagley, inicialmente trabalhando com bolsa da Guggenheim e depois como funcionário do SESP em Belém, e Heloisa (Correa \& Melo 2008). Sendo assim, no ano seguinte não se encontram nos arquivos da Smithsonian documentos sobre o ISA no Brasil, e os fatos concretos da cooperação latino-americana após a fundação do ISA remetem imediatamente ao México, como exposto no próximo item.

A cooperação com a ELSP, iniciada no Brasil em outubro de 1945, quando Pierson foi designado representante do ISA no Brasil, consolidou-se como um modelo de cooperação da política de boa vizinhança. O relatório da SI de 1947 enfatiza que o programa desenvolvido pelo ISA na Smithsonian começou quando Pierson (SI 1948:62) chegou em São Paulo em 1939, atuando na ELSP desde sua chegada e contribuindo para que ela se tornasse um dos mais importantes centros de ciência social na América do Sul. A partir de 1945, dirigiu o programa de estudos de Pós-graduação em Antropologia, vinculado ao ISA. Os primeiros títulos de mestrado foram concedidos em fevereiro de 1946. Paralelamente às atividades de ensino, os membros do ISA conduziram um programa de apoio ao ensino através de traduções de 200 artigos e 13 livros do inglês para o português, bem como a publicação de resultados de pesquisa em inglês e francês. Fundos extramuros financiaram publicações como a Coleção de Ciências Sociais, criada por Pierson, que foi fundamental na elaboração de um campo editorial específico em ciências sociais no Brasil. Era convicção de Pierson que os estudantes deviam ser treinados em técnicas de pesquisa de campo durante os cursos, sendo importante incentivá-los a conduzir surveys em Mato Grosso e em áreas rurais perto de São Paulo, mas, além disso, em áreas mais distantes, como o projeto de pesquisa no rio São Francisco (Correa 1987).

Kalervo Oberg, designado como antropólogo cultural e cooperando com a ELSP, tratou do mal-estar dos estadunidenses transportados para outros países a partir de uma noção formulada por Cora Dubois no primeiro encontro do Instituto Internacional de Educação, em 1951, em Chicago. Em comunicação apresentada em clube feminino no Rio de Janeiro, em 1954, Oberg (1954) definiu "choque cultural" como reação precipitada pela an- 
siedade que resulta no lapso de todos os signos que permitem reconhecer pessoas como familiares e de símbolos que facilitam a interação social, levando à perda da orientação na vida cotidiana. Ainda que pesquisadores que atuavam no México, no Brasil ou em outros países da América do Sul pudessem se considerar apolíticos ou indiferentes, ou mesmo atuarem como agentes dissidentes de tais políticas, partilhavam com os estadunidenses o ethos de seu país, o que os levava a ver os latino-americanos hierarquicamente, através de estereótipos, excluindo-os de seus projetos de carreira nas instituições norte-americanas.

\section{O ISA e o México}

Em setembro de 1943 Steward tornou-se diretor do ISA. A presença de pesquisadores estadunidenses em cada país era legalmente baseada em um convênio, um acordo assinado pelo ministro das Relações Exteriores do país envolvido e pelo Departamento de Estado norte-americano. A demanda inicial para a participação dos Estados Unidos veio de cada país latinoamericano. O convênio estabelecia o período de colaboração acordado, a contribuição a ser dada por cada governo e os termos gerais de cooperação. O acordo era semelhante em todos os países: os Estados Unidos iriam recrutar pessoal próprio, pagar seus salários, despesas e custos de campo e publicar em inglês os resultados da pesquisa de campo. As instituições locais participantes iriam fornecer espaço em sala para trabalho, salas de aula, auxiliares de ensino, bem como financiar as despesas de pesquisa de campo. As áreas onde as pesquisas se realizariam seriam definidas em comum acordo pelas instituições locais e os pesquisadores norte-americanos. Os pesquisadores estadunidenses não poderiam chegar aos países latino-americanos antes de aprovação oficial dada pelos governos locais. Os governos que hospedariam os pesquisadores teriam, portanto, poder de veto e, deste modo, um grau considerável de controle sobre os participantes dos Estados Unidos.

As diretrizes do ISA foram estabelecidas em consonância com as determinações do Joint Commitee on Latin American Studies (JCLAS), que foi instituído em 29 de março de 1942, traçadas sob a direção de Robert Redfield, com o objetivo de promover e coordenar a atividade acadêmica no campo latino-americano (Redfield 1943:3). Era dada ênfase especial ao papel de uma rede de cientistas sociais especializados na América Latina para fornecer treinamento e serviços gerais que pudessem viabilizar as atividades da guerra. O México era considerado especialmente estratégico neste sentido, uma vez que era uma área que vinha sendo sistematicamente estudada por 
acadêmicos dos EUA e, sendo assim, não foi à toa que Redfield, com larga experiência no país, já atuando como professor consagrado na Universidade de Chicago, dirigiu o JCLAS, ocupando lugar central na coordenação de atividades na América Latina.

Steward visitou o México em setembro de 1943, quando estabeleceu os termos de um acordo para o trabalho do Instituto com autoridades da Escola Nacional de Antropologia e do Instituto Nacional de Antropologia e História, submetendo este acordo ao Departamento de Estado dos Estados Unidos antes do fim de setembro. O fato de que o acordo demorou alguns meses para se completar denota algumas arestas a serem aparadas no tocante à interpretação dos mexicanos sobre as bases da cooperação. Contudo, pesquisadores dos EUA encontravam no país um lastro pré-constituído por meio dos estudos de comunidade de Robert Redfield (1930) e da antropologia da ação de Sol Tax. Os estudos de Redfield pautaram-se por um estilo acadêmico na busca de distinções claras entre categorias sociais que fundaram os peasant studies (estudos de campesinato) enquanto entidades isoladas, com base na diferenciação da cultura folk, da cultura "civilizada". Sol Tax definiu a "antropologia da ação" como um método experimental de estudo indissociável da pesquisa de campo propriamente dita, como uma atividade não utilitária que combinasse aprender e ajudar e na qual nenhuma destas práticas fosse dominante. A par da constatação de que conhecimento é poder, buscava-se renunciar a este, com uma postura ética de busca da verdade (Tax 1952, 1975:516). Já Julian Steward propunha formar recursos humanos em antropologia social, tendo em vista a utilização do "conhecimento antropológico sobre mudança cultural e desenvolvimento para servir de base para planejadores profissionais" (Foster 1989:135). Posteriormente, Foster viria a avaliar a busca de aplicação da antropologia notadamente no campo da antropologia médica, o que constituiria um foco central de sua atuação no ISA (Figueiredo 2009). De acordo com este autor, foi a própria situação de guerra que fez com que os antropólogos estadunidenses buscassem a tomada de consciência das possibilidades existentes (ibidem:120).

A revista América Indígena publicou artigos que emergiram da polêmica sobre antropologia aplicada, escritos por Julian Steward $(1941,1943)$, John Collier (1941), Sol Tax (1942) e Robert Redfield (1943). Collier era um antropólogo que não atuava propriamente no campo universitário, mas sim dirigindo o Bureau of Indian Affairs (BIA), um escritório encarregado da política indigenista dos EUA (Blanchette 2006), entendida como uma agência de diplomacia interna que lidava com questões práticas visando atuar como uma instância de legitimação da política indígena. Sol Tax advogava a importância de considerar a política indígena em termos do que de fato 
estava acontecendo, sem se prender a interpretações do passado, buscando identificar qual a diferença entre os índios e os antropólogos nos projetos de antropologia da ação (Tax 1957). Já Robert Redfield colocava acima de tudo o compromisso dos antropólogos com o organismo federal encarregado do indigenismo de Estado no México. Expondo divergências com seus interlocutores acadêmicos, Steward apresentava-os como ativistas, apontando em seus textos uma contradição potencial entre ação como cientista e como cidadão. Identificando antropologia social com ciências naturais, Steward advogava que a antropologia aplicada deveria se fundamentar mais em generalizações científicas do que em problemas éticos. Tanto Steward quanto seus interlocutores, em seus estudos de campo, consideravam heuristicamente as "comunidades indígenas" como unidades de análise que existiam em um relativo isolamento em face dos mercados e da sociedade envolvente. Cabe indagar em que medida seria possível delimitar a linha divisória entre ética e política e evitar o risco de entrar em contradição com os princípios éticos e de humildade cognoscente prescritos pela antropologia da ação de Sol Tax.

Em 1943, após mais ou menos dois anos de ensino pós-doutoral em Siracusa, Los Angeles e Berkeley, Foster foi contratado como analista do Institut of Interamerican Affairs em Washington, tendo oportunidade de observar de dentro como a classificação social funcionava na burocracia, o que veio a analisar mais detidamente muitos anos depois, quando tratou de sua experiência institucional na área de antropologia da saúde pública (Foster 1987).

George Foster e Donald Brand chegaram ao México em maio de 1944, tendo que esperar a contragosto até então porque os governos do México e dos EUA demoraram a concluir o convênio que administraria os termos de cooperação. Foster permaneceu em Washington no período, na expectativa de se desvencilhar do alistamento obrigatório para a guerra, do qual foi liberado porque foi detectada alergia. Afirma Foster que esperava que o acordo fosse assinado rapidamente, mas teve que esperar meses e meses até que o convênio fosse assinado pelo governo dos EUA e o governo do México (Foster 1989:124). Engajado como responsável pelo instituto no México, procurou iniciar as atividades de cooperação assim que chegou. Mas suas dificuldades com a burocracia não terminaram quando alcançou o destino pretendido: teve que se contentar em dividir a sala com o diretor da Escuela, Daniel F. Ruben de la Borbolla, enquanto superava etapas imprescindíveis antes da almejada pesquisa de campo. Foster apresenta uma disposição para acreditar que as respostas dependem de interpretação. Afirma ele: Donald Brand (que também representou o instituto como geógrafo cultural) e eu "pensamos o pior, porque no convênio os direitos de ambas as partes eram detalhadas, 
especificando um escritório para professores visitantes americanos. Então, quando percebemos que não havia nenhuma sala disponível para nós, sentimos que estávamos sendo mandados embora. Mais tarde nos demos conta de que a burocracia mexicana era pior do que a nossa e que eles estavam fazendo o melhor que podiam" (Foster 1989:125). A tolerância de Foster em relação à precariedade de uma situação aparentemente irracional e contraditória com o que havia sido assinado no acordo denota seu entendimento sobre a necessidade de partilhar a escassez em vez da ruptura que viesse a minar a cooperação. Podemos ver em sua "boa vontade" na interação com a mentalidade local uma ressonância da interpretação das orientações cognitivas do camponês mexicano sobre o "bem limitado". Tal disposição denota uma sensibilidade especial em tempos de guerra, quando a partilha de bens escassos seria uma alternativa radical ao espectro de ambição e avareza estimulado pela visão predominante no Primeiro Mundo quando recursos naturais eram considerados ilimitados, requerendo-se apenas conhecimento e habilidade para explorá-los (Nash 2007:36).

De fato, era Foster quem tinha grande expectativa pela interação com a antropologia mexicana, que ele visualizava com muito mais a oferecer do que pesquisadores de campo. Afirma ele: "o México era o primeiro país latino-americano a se tornar independente em antropologia. Eles estavam construindo um grande centro antropológico. Havia muita gente realmente competente, pesquisadores de alta classe". Já desfrutara a amizade de muitos deles em sua estadia para a pesquisa para o doutorado, e que foram seus colaboradores na Escuela, como Wigberto Moreno, Alfonso Caso e Miguel Covarrubias. Para Foster, estes antropólogos que buscavam construir um ethos fundamentado pelo nacionalismo cultural viam a antiguidade arqueológica como um elemento a ser acionado na luta para identificarem-se a si mesmos como um grupo distinto de outros grupos, como uma forma de construir a identidade tendo como base a evidência física da grandeza passada: dos Maias, dos Astecas e dos Toltecas. Reconhecendo isto, o governo mexicano havia incentivado a arqueologia desde o século XIX.

Durante metade do ano eles se dedicaram ao ensino de antropologia na Escuela e durante a outra metade supervisionaram uma equipe em sua pesquisa de campo entre aldeias Tarascan em Michoacán. A equipe de campo consistia em estudantes do México e de outras repúblicas americanas, incluindo Guatemala, Costa Rica, Panamá, Colômbia, Espanha, França, Canadá e Estados Unidos. A Escuela publicou muitos trabalhos acadêmicos de seus estudantes e professores. Foster (1967) expôs, exploratoriamente, problemas éticos e profissionais da pesquisa e da preparação profissional de antropólogos referentes à filosofia, ao funcionamento, ao modo de operação 
e aos resultados do ISA. Entre os pesquisadores estrangeiros, estiveram no México: Franz Boas (1911-1912), Edward Seler, Alfred Tozzer e J. Alden Mason. Durante o estabelecimento do ISA, atuaram no México professores da Universidade de Chicago, como Sol Tax, que ensinou na Escuela Nacional de Antropología e Historia e engajou-se em pesquisa de campo em Chiapas com estudantes latino-americanos.

O ISA manteve sua sede em Washington para planejamento geral, direção e orientação de projetos de campo. Julian Steward renunciou ao cargo de diretor do ISA em setembro de 1946, quando passou a exercer a função de professor no Departamento de Antropologia da Universidade de Columbia. Seu sucessor foi George Foster, que foi substituído em sua posição de coordenação do ISA, no México, por Isabel Kelly, que lá atuou de julho de 1946 a dezembro de 1952. A dimensão ética do tratamento dado aos legados das pesquisas de Foster e Kelly para as instituições mexicanas é exposta em Kemper (2007) e Kemper \& Royce (2007).

Foster afirma que, quando chegou ao México, em 1940, para a pesquisa de campo para seu doutorado, não era politizado, apenas queria aprender espanhol. No entanto, em sua vida de estudante, conheceu intelectuais mexicanos, mencionando Antônio Caso, um filósofo irmão do arqueólogo Alfonso Caso. Frequentou as reuniões da Sociedade Mexicana de Antropologia que se reunia todos os meses. Menciona, entre os antropólogos mexicanos que conheceu na época preocupados em promover o reconhecimento das artes e dos costumes mexicanos, Wigberto Jiménez Moreno, que tratou, nos anos 1920, dos limites culturais da afinidade cultural como um traço distintivo da cultura meso-americana, que foram a base para os estudos de área desenvolvidos nos anos 1940 (Austin \& Luján 2001:45). O arqueólogo Manuel Caso desempenhou um papel de fundamental importância no sentido de instrumentalizar a antropologia para a fundação do Instituto Indígena Interamericano no México, imprimindo-lhe uma conotação bem diferente da visão que os estadunidenses tinham de seus índios (Foster 1989:87).

Manuel Gamio (1883-1960) estudou de 1909 a 1911 na Universidade de Columbia sob a orientação de Franz Boas no campo da arqueologia, sendo o primeiro pesquisador latino-americano a receber o grau de doutorado em antropologia nos EUA. Gamio ocupou muitas posições acadêmicas e políticas: diretor da Escuela Internacional de Antropología y Etnografía Americana (1916-1920); diretor de antropologia da Secretaria de Agricultura do México (1917-24) e diretor do Instituto Indigenista Interamericano (1942-1960). Nos anos 60 diversos autores atestaram que Gamio não foi o único fundador da antropologia nacionalista e indigenista no México. Cita-se, entre outros, Andrés Molina Enriquez que, como chefe do Departamento de Etnologia 
do Museu de Antropologia e História do México, promoveu a ideia de etnologia aplicada. Os antropólogos mexicanos, que colocavam os problemas indígenas no cerne da construção nacional mexicana, eram tidos, todavia, mais como "informantes" do que como propriamente interlocutores, ainda que tenham sido citados nos trabalhos da SI. Os estudos sobre arqueologia e cultura olmeca apresentados por Alfonso Caso (1942) e Miguel Covarrubias (1942) na reunião da Mesa Redonda sobre "Problemas Antropológicos de México y Centro América-Tuxtla Gutiérrez em Chiapas" são mencionados na página da Smithsonian Institution, na qual são disponibilizadas informações do inventário sobre o legado olmeca promovido pela SI sob a liderança de Philip Drucker, Robert Heizer e Matthew Stirling. No entanto, a imagem apresentada neste site é a de que os antropólogos mexicanos corroboravam as investigações dos estadunidenses.

O interesse arqueológico, tradicional no México, foi redimensionado por autores nacionalistas como Caso, que construiu uma história cultural do México informada simultaneamente pelo evolucionismo cultural e pelo funcionalismo, enfatizando o papel das elites no desenvolvimento mexicano (Patterson 1995:310). Enquanto isto, intelectuais que participavam da construção nacional no México valorizaram as raízes indígenas, sem sair, contudo, da "jaula de ferro" da burocracia criada pelo Estado nacionalista, ou minimizar as radicais diferenças entre as elites e os diversos povos indígenas que continuavam sendo expropriados dos meios de produção e relegados dos processos políticos de decisão.

Mesmo contraditório, o engajamento político dos antropólogos mexicanos não era facilmente assimilado pelo código de valores da cúpula de Washington. Castañeda (2005) examina como a máquina de obtenção de informações funcionou na Carnegie Institution of Washington (CIW), inicialmente uma instituição filantrópica não governamental que, nos anos 1940, se colocou a serviço do governo dos EUA para financiar pesquisas visando obter conhecimento detalhado sobre as ações de arqueólogos ativistas do indigenismo mexicano. Estes, seguindo as concepções de Gamio, viam que a ciência deveria promover a cidadania e a valorização positiva da nacionalidade. A pesquisa básica, para o autor de Forjando pátria, deveria estar a serviço da intervenção revolucionária, contrariamente à visão predominante nos EUA, segundo a qual a ciência deveria servir como instrumento de controle social, através das estatísticas, da vigilância e da adequação política das instituições às metas de governo (Castañeda 2005:37). Na sua colaboração com o esforço de guerra, a CIW mobilizou-se como um centro de orquestração da pesquisa militar industrial com base na interação entre militares, cientistas, homens de negócio e dirigentes governamentais na formação de um 
sistema de espionagem que visava identificar ações consideradas perigosas para a consecução de programas de produtividade necessários aos objetivos hegemônicos dos EUA. Foster não podia deixar de saber como tal vigilância se estabelecia. Ainda que não conste ter participado diretamente das ações de espionagem, evidencia-se a dubiedade de sua posição, ao mesmo tempo se pretendendo "apolítico" para se manter no cargo de uma instituição concebida para exercer o papel de mediadora das diretrizes orquestradas de Washington e dos programas de pesquisa no México.

\section{Conclusão}

A proposta de uma colaboração científica simétrica na criação de escritórios do ISA no Brasil e no México foi atravessada por assimetrias entre "Vizinhos do Norte" anglo-americanos e seus vizinhos da América hispânica no México e da América luso-brasileira no Brasil. Embora, desde a independência do Brasil, os EUA tivessem se posicionado como aliados potenciais, não houve uma ruptura com a cultura europeia nos mesmos moldes mexicanos. Os estudos antropológicos desenvolvidos por Roquette Pinto e Heloisa Alberto Torres vieram, contudo, a incentivar a pesquisa de campo e a formação de novos antropólogos no Museu Nacional. A instituição interagiu com projetos desenvolvidos no Departamento de Antropologia da Universidade da Columbia, o que implicou a presença no Museu Nacional de pesquisadores relacionados com Franz Boas. Os pesquisadores brasileiros atuaram como representantes de pesquisas estadunidenses, cujos resultados se mostravam promissores do ponto de vista da antropologia social. Os laços estabelecidos não foram suficientes para gerar a confiança para a consolidação de uma colaboração com a Smithsonian, de modo geral, em termos da criação do escritório do ISA no Museu Nacional. Tal escritório, afinal, foi fundado na ELSP, onde Donald Pierson parecia ser a pessoa indicada para representar o que Steward almejava em termos de uma cooperação institucional continuada.

As relações de colaboração entre professores estadunidenses e alunos latino-americanos não podiam deixar de ser pautadas pela hierarquia científica, ao passo que os brasileiros que atuavam como fiscais - representando os interesses de salvaguarda do patrimônio cultural brasileiro - nas expedições de pesquisadores estrangeiros não podiam, quando defendiam valores nacionais, deixar de ser vistos como representantes de um Estado autoritário e elitista. Os pesquisadores anglo-americanos, que reproduziram a tradicional divisão de trabalho intelectual — entre trabalho de gabinete e trabalho de campo - estavam envolvidos com os projetos de colaboração 
internacional, sendo vistos como agentes intervenientes privilegiados, imbuídos de um paternalismo hierárquico, e que viam os seus colaboradores sul-americanos como imersos na construção nacional, uma vez que tinham sido recrutados para o serviço do Estado. Estes, no entanto, viam-se aprisionados na jaula de ferro da burocracia estatal, em sociedades atravessadas por relações patriarcais.

As relações internacionais, na fundação do ISA, foram constituídas em um momento em que não mais se podia propriamente falar em situações coloniais. Mas não se pode tampouco negar o paternalismo e as hierarquias que perpassavam a cooperação científica entre instituições estadunidenses como a Smithsonian e centros de pesquisa recém-formados em países latinoamericanos como o Brasil e o México. No entanto, no estilhaçar de valores da situação de guerra, era compreensível o "choque cultural" dos pesquisadores anglo-americanos que se deparavam com situações de colonialismo interno e lutas por posição envolvendo disputas inter-regionais e disputas interinstitucionais, nas quais não podiam deixar de estranhar os discursos nacionalistas que impregnavam as reivindicações de autonomia. Mas após esta experiência em terra estrangeira, seguramente passaram também a ver com outros olhos suas disputas e seus próprios discursos sobre a nacionalidade. Eventualmente perceberam, em suas posições acadêmicas conquistadas durante a Guerra Fria, que mesmo o cientista mais isento também mistura racionalidade e emoção, de modo semelhante àquele em que os cientistas sociais brasileiros e mexicanos se deixavam influenciar pelas motivações políticas dos discursos produzidos no âmago do nacionalismo.

O fato de as pesquisas de então terem passado a ser geridas dentro de uma máquina de engenharia científica que articulava funções técnicas, utilitárias e políticas, expressando uma tensão entre reivindicação de pesquisa básica e demandas por aplicabilidade da ciência, não impediu que os antropólogos se impusessem pensamentos de ordem moral e ética. Ainda que não discutidos de modo sistemático, os dilemas éticos vividos pelos antropólogos nos preâmbulos da Guerra Fria mostraram a sobrevida das teses boasianas do relativismo e da diferença cultural. Mais do que nunca, porém, o campo científico mostrou-se articulado ao político, apresentando as demandas de autonomia intelectual em sua relatividade. Esses tempos do despertar da Guerra Fria foram o começo do que se entende hoje como usos sociais da ciência como assunto de matéria prática. 
Recebido em 07 de junho de 2010

Aprovado em 26 de abril de 2011

Priscila Faulhaber é pesquisadora do MAST. E-mail: <priscila@mast.br>

\section{Referências bibliográficas}

AUSTIN, Alfredo López \& LUJÁN, Leonardo López. 2001. Mexico 's indigenous past. Noman: University of Oklahoma.

BATALLA, Guilhermo Bonfil. 1996. Mexico profundo. Reclaming a civilization. Austin: University of Texas Press

BLANCHETTE, Thaddeus Gregory. 2006. Cidadãos e selvagens: antropologia aplicada e administração indígena nos Estados Unidos, 1880-1940. Tese de Doutorado, PPGAS/Museu Nacional/ UFRJ.

BOURDIEU, Pierre. 1982. Esboço de uma teoria da prática. Oeiras: Celta.

CAMPOS, André Luiz Vieira. 2006. Políticas internacionais de saúde na Era Vargas. O Serviço Especial de Saúde Pública, 1942-1960. Rio de Janeiro: Editora da Fiocruz.

CÂNDIDO, Antônio. 1979. "Prefácio". In: S. Miceli (org.), Intelectuais e classe dirigente no Brasil (1920-1945). São Paulo: Difel. pp. IX-XIII.

CARDOSO DE OLIVEIRA, Roberto. 1978 [1966]. "A noção de colonialismo interno na etnologia" In: Sociologia do Brasil Indígena. Rio de Janeiro: Civilização Brasileira/ Brasília: Tempo Brasileiro. pp. 75-82.

CASANOVA, Pablo Gonzáles. 1962. “Sociedad plural, colonialismo interno y desarrollo". Revista America Latina, 3(6):1-24.
CASO, Alfonso. 1942. "Definición y extensión del complejo 'Olmeca'". In: Mayas y Olmecas: segunda reunión de mesa redonda sobre problemas antropológicos de México y Centro América-Tuxtla Gutiérrez/ Chiapas. México: Sociedad Mexicana de Antropología. pp. 43-46.

CASTAÑEDA, Quetzil E. 2005. "The Carnegie Mission and vision of scientific institutional contexts of maya archeology and espionage". In: Regna Darnell \& Frederic Gleach (eds.), Histories of anthropology, annual volume I. Lincon \& London: University of Nebrasca Press. pp. 27-60.

CASTRO, Peter A. 2010. "Collaborative researchers or cold warriors? The origins, Activities, and legacy of the Smithsonian's Institute of Social Anthropology". Journal of International and Global Studies, 2(1):56-82.

CASTRO FARIA, Luis. 1978. "Heloísa Alberto Torres (1985-1977)". Anuário Antropológico,77:329-33.

COLLIER, J. 1941. “Nuevos conceptos sobre la unidad indígena". América Indígena, 1(1):11-16.

CORREA, Mariza. 1987. História da antropologia no Brasil (1930-1960): testemunhos. Campinas: Editora da Unicamp/Editora Vértice. . 1997. "Dona Heloísa e a pesquisa de campo". Revista de Antropologia, 
40(1). Disponível em: http://www. scielo.br/pdf/ra/v40n1/3240.pdf. Acesso em 29/09/2009.

. 2000. "O mistério dos orixás e das bonecas: raça e gênero na antropologia brasileira". Etnográfica, 4(2) :223-265.

2003. Antropólogas e antropologia. Belo Horizonte: Editora da UFMG.

CORREA, Mariza \& MELO, Januária (orgs.). 2008. Querida Heloisa/Dear Heloisa. Cartas de campo para Heloisa Alberto Torres. Núcleo de Estudos de Gênero - Pagu, Série Pesquisa, Campinas, UNICAMP. Acessado eletronicamente em 22/04/2011.

COVARRUBIAS, Miguel. 1942. "Origen y desarrollo del estilo artístico 'Olmeca'". In: Miguel Covarrubias (ed.), Mayas y Olmecas: segunda reunión de mesa redonda sobre problemas antropológicos de México y Centro América-Tuxtla Gutiérrez, Chiapas. México: Sociedad Mexicana de Antropología. pp. 46-49.

DELPAR, Helen. 2008. Looking south: the evolution of latin americanist scholarship in the United States, 18501975. Tuscaloosa: The University of Alabama Press.

ELIAS, Norbert. 1982. "Scientific establishments". In: Norbert Elias, Herminio Martins \& Richard Whitley (eds.), Scientific establishments and hierarchies. Dordrecht, Boston and London: D. Reidel Publishing Company. pp. 3-70.

ERB, Claude Curtis. 1982. Nelson Rockefeller and United States-Latin American relations, 1940-1945. PhD Dissertation, Clark University, Worcester, Massachussets.

FIGUEIREDO, Regina Erika Domingos. 2009. Histórias de uma política de "boa vizinhança": um estudo sobre o papel dos antropólogos nos programas interamericanos de assistência técnica e saúde no Brasil e no México (1942-1960). Tese de doutorado, Campinas, Unicamp.

FOSTER, George. 1967 ."The Institute of Social Anthropology of the Smithsonian Institution". Anuário Indigenista, 27:173-192.

1987. "Bureacratic aspects of International Health Agencies". Social Science and Medicine, 25(9):10391048.

1989. "An anthropologist's life in the 20th century: theory and practice at UC Berkeley, the Smithsonian, in Mexico, and with the World Health Organization". Regional Oral History Office. Entrevistas concedidas a Suzanne Riees em 1988 e 1989. Bancroft Library da Universidade da Califórnia em Berkeley. Disponibilizado on-line em: http://www.archive.org/ details/anthrolife00fostrich. Acessado em 29/9/2009.

GAVIN, Smith; NUGENT, David \& VINCENT, Joan. 2004. A companion to the anthropology of the politics. Malden, Oxford: Victoria/Blackwell. pp. 216230.

HYMES, Dell. 1967. "The use of anthropology: critical, political, personal". Reinventing anthropology. New York: Panteon. pp. 4-79.

KEMPER, Robert. 2007. "Being a steward of what is left behind: the ethnographic legacies of Isabel T. Kelly e George M. Foster" (digit). In: George Stocking Simposium on History of Anthropology. Washington: AAA. pp. 1-8.

KEMPER, Robert \& ROYCE, Anya P. 2007. "Ethical issues for social anthropologists: a north american perspective on long-term research in Mexico". Human Organization, 56(4):479483.

KERNS, Virginia. 2003. Scenes from the high desert. Julian Steward 's life and 
theory. Urbana and Chicago: University of Illinois Press.

LIMA, Antonio Carlos de Sousa. 2005. "Indigenism in Brazil. The international migration of state policies". In: Benoît de L'Estoile, Federico Neiburg, Lygia Sigaud (eds.), Empires, nations, and natives. Anthropology and state making. Durham\&London: Duke Univerisity Press. pp. 196-222.

LOMNITZ, Claudio. 2005. "Bordering on anthropology: dialectics of a national tradition in Mexico". In: Benoît de L'Estoile, Federico Neiburg \& Ligia Sigaud (eds.), Empires, nations, and natives. Anthropology and state making. Durham\&London: Duke Univerisity Press. pp. 167-196.

MAINGUENEAU, Dominique. 1989. Novas tendências em análise de discurso. Campinas: Pontes.

MARTINELLO, Pedro. 2004. A batalha da borracha na Segunda Guerra Mundial. Rio Branco: Edufac.

MASSI, Fernanda. 1989. "Franceses e norte-americanos nas ciências sociais brasileiras (1930-1960)". In: Sergio Miceli (org.), História das ciências sociais no Brasil. Vol. 1. São Paulo: Vértice/Idesp. pp. 410-460.

NASH, June. 2007. "The notion of the limited good and the specter of the unlimited good". In: Practicing ethnography in a globalizing world. An anthropological odissey. Lanham: Altamira Press. pp. 35-54.

NEEDLER, Martin. 1967. Latin american politics in perspective. Princeton, New Jersey: D. Van Nostrand Company,

NEIBURG, Federico \& GOLDMAN, Márcio. 1998. "Anthropology and politics in studies of national character". Cultural Anthropology, 13(1):56-81.

OBERG, Kalervo. 1954. "Culture shock". Disponível em: http://www.smcm. edu/Academics/internationaled/Pdf/ cultureshockarticle.pdf. Acesso em 29/9/2009.

PATTERSON, Thomas C. 1995. "History, indigenism and the state in Peru and Mexico". In: \& Peter R. Smith (eds.), Making alternative stories. The practice of archeology and history in non-western settings. Santa Fe: School of American Research Press. pp. 69-86.

. \& Lauria-Parricelli, Antonio. 1999 "Julian Steward and the construction of area-studies research in the United States". In: Richard O. Clemmer; L. Daniel Myeres \& Mary Elizabeth Rudden (eds.), Julian Steward and the great basin. Utah: University of Utah Press. pp. 219-240.

PEIRANO, Mariza. 1999. "A antropologia no Brasil (alteridade contextualizada)". In: Sérgio Miceli (org.), O que ler na ciência social brasileira (1970-1995). São Paulo: Sumaré. pp. 225-266.

1981. The anthropology of anthropology. The Brazilian case. Ph.D. thesis, Universidade de Harvard, Cambridge.

PRICE, David H. 2008. Anthropological intelligence. The deployment and neglect of American anthropology in the Second World War. Duke: Duke University Press.

REDFIELD, Robert.1943."Comments on Dr. Tax's article". America Indigena, 3:83-86.

. 1943. "The Joint Committee on Latin American Studies". Notes on Latin American Studies, 1:3-6.

ROSALDO, Renato. 2003. Culture \& truth: The remaking of social analysis. Boston: Beacon Press.

ROSEBERRY, William. 1994. "Hegemony and the language of contention". In: G. M. Joseph \& Daniel Nugent (eds.), Everyday forms of state formation: revolution and the negotiation of rule 
in modern Mexico. Duhan, NC: Duke University Press. pp. 355-366.

ROSS, E. (2008). "Peasants on the minds: Anthropology, the Cold War, and the myth of peasant conservatism". In: D. Wax (ed.), Anthropology at the dawn of the Cold War: The influence of foundations, McCarthyism, and the CIA. London: Pluto, pp. 88-107.

SAID, Edward W. 1996. Representations of the intellectual. New York: Vintage Books.

SYER, Derek. 1994. "Everyday forms of state formation: some dissident remarks on "hegemony". In: G. M. Joseph \& Daniel Nugent (eds.), Everyday forms of state formation: revolution and the negotiation of rule in modern Mexico. Duhan, NC: Duke University Press. pp. 367-377.

SMITHSONIAN INSTITUTION. 1945. Reports of the Bureau of American Ethnology. Washington: Smithsonian Institution.

1946. Reports of the Bureau of American Ethnology. Washington: Smithsonian Institution.

1948. Reports of the Bureau of American Ethnology. Washington: Smithsonian Institution, Bureau of American Archeology. Disponível em: http:// anthropology.si.edu/olmec/espanol/index.htm. Acesso em 29/9/2009.

STEWARD, Julian H. (ed.). 1948. Handbook of south american indians. The tropical forest tribes. vol. 3. Washington: Smithsonian Institution. . 1941. "The handbook of south american indians". América Indígena, 1(1):47-50. Instituto Indigenista Interamericano, México.

1943. "Acculturation and the indian problem". América Indígena, 3(4):323328.

. 1955. Theory of culture change. Illinois: University of Illinois Press.
STOCKING, George W. 1968. "The scientific reaction against cultural anthropology 1917-1920". In: Georg Stocking (ed.), Race, culture, and evolucionism: essays in the history of anthropology. Chicago: University of Chicago Press. pp. 270-307.

TAX, S. 1942. "Ethnic relations in Guatemala". América Indigena, 2(4):4347.

1952. "Action anthropology". América Indigena, 12:103-106.

1957. "Federal Indian policy and the National Congress of American Indians(NCAI)". Edited version of an impromptu speech delivered at the NCAI convention, Washington, 1957. Distributed by the NCAI. . 1975. "Action anthropology". Current Anthropology, 16(4):514-517.

THOMPSON, Eric. 1963. The making of English working class. New York: Vintage.

WAGLEY, Charles. 1953. Amazon town. A study of man in the tropics. New York: The Macmillan Company.

WAX, D. (ed.). 2008. Anthropology at the dawn of the Cold War: the influence of foundations, mccarthyism, and the CIA. London, UK: Pluto.

WILLIAMS, Raymond. 1977. Marxism and literature. Oxford: Oxford University Press.

WILLIGEN, John. 2002. Applied anthropology. An introduction. Westport: Greenwood Publishing Group. 
Resumo

O presente trabalho trata do estabelecimento de escritórios do Instituto de Antropologia Social da Smithsonian Institution (SI) no México e no Brasil. A presença da SI dependia de acordos diplomáticos que requeriam aceitação pelos países hospedeiros. O trabalho focaliza documentos, tais como entrevistas e registros institucionais, analisados segundo a relação entre discursos e práticas envolvidos na resposta antropológica ao esforço de guerra. Tal análise pressupõe um entendimento de conceitos empregados na época como "antropologia aplicada", "estudos de área", "estudos de comunidade" e definições usadas especificamente por antropólogos da SI, como "bem limitado" e "choque cultural". O método comparativo mostra-se relevante para entender o que se passava nos dois países. No México, negociações políticas e outros fatores retardaram a criação do Instituto. No Brasil, o processo envolveu disputas interinstitucionais. O exame dessas interações leva à análise da maneira hierárquica como o Instituto era apresentado.

Palavras-chave Pan-americanismo, Esforço de Guerra, Discursos dos Cientistas Sociais, Método Comparativo, Patrimônio Científico, Choque Cultural

\section{Abstract}

This paper examines the establishment of offices of the Smithsonian Institute of Social Anthropology (ISA) in Mexico and Brazil. The Smithsonian's presence depended on diplomatic agreements that required acceptance from the host countries. The article analyzes written documents such as interviews and institutional records to explore the relationship between the discourses and practices involved in the anthropological contribution to the US war effort. This analysis presumes a basic understanding of concepts used at the time, such as 'applied anthropology,' 'area studies' and 'community studies,' as well as definitions specifically used by the Smithsonian's anthropologists, such as 'limited good' and 'culture shock.' The comparative method is relevant to understanding what happened in the two countries. In Mexico, political negotiations and other factors delayed its implantation. In Brazil the process involved inter-institutional disputes. A closer look at these interactions leads to an analysis of the hierarchic interrelationships involved in the creation of the Institute.

Key words Pan-Americanism, War Effort, Discourses of Social Scientists, Comparative Method, Scientific Heritage, Culture Shock 